\title{
Matrix of Personality Intelligent Characteristics as an Instrument for Its Development Management
}

\author{
Sviatoslav Kis \\ Department of Economics and \\ Management Theory \\ Ivano-Frankivsk Natonal Technical \\ University of Oil and Gas \\ Ivano-Frankivsk, Ukraine \\ svjatkis@gmail.com \\ Oleh Yatsiuk* \\ Department of Economics and \\ Management Theory \\ Ivano-Frankivsk Natonal Technical \\ University of Oil and Gas \\ Ivano-Frankivsk, Ukraine \\ olegstya@gmail.com \\ https://orcid.org/0000-0002-3943-7352
}

\author{
Galyna Malynovska \\ Department of Economics and \\ Management Theory \\ Ivano-Frankivsk Natonal Technical \\ University of Oil and Gas \\ Ivano-Frankivsk, Ukraine \\ oleg_st_ya@yahoo.com
}

\author{
Victor Petrenko \\ Department of Public Administration \\ and Management \\ Ivano-Frankivsk Natonal Technical \\ University of Oil and Gas \\ Ivano-Frankivsk, Ukraine \\ ipo.pvp@gmail.com
}

\begin{abstract}
The human capital of any organized community of people serves as the main resource of its development and competitiveness as an economic system, and its ability to create, develop and effectively use such a non-material kind of capital as human will determine its economic power and market success. The purpose of this paper is to create an intellectual characteristics model of of human capital elementary carrier as a tool for managing the processes of planning, formation, development and efficient use of enterprise human capital.
\end{abstract}

The proposed planar or spatial matrices proposed by the authors can be a useful tool for managing the processes of creating, developing and using any components of enterprise intangible capital (human, intellectual, social, etc.). These components determine the possibilities for improving the characteristics of the individual (or their groups) through the achievement of education, qualifications, knowledge, experience required level and, accordingly, the ability of their carriers to productive, efficient and high-quality work. Classical methods of research work such as analysis, synthesis, comparison, graphical representation were used during processing.

Keywords-human capital, intellectual capital, social capital, personality intellectual characteristics, development management

\section{INTRODUCTION}

The proper management problems for formation, development and effective use of enterprise human capital (HC) processes have long been the main subject of a large number of theoretical studies, scientific publications with conceptual, methodological and practical character of scientists from different countries. After all, the human capital of any organized people community is the main resource of its development and competitiveness as an economic system, and its ability to establish, develop and effectively use such intangible type of capital as human will determine its economic power and market success. In this regard, the recent attention of the world of scientists is concentrated on the problems of establishing the qualitatively new human productive abilities wich are necessary in the production and labor market.

\section{ANALYSIS OF RECENT RESEARCH AND PUBLICATIONS}

Recently, domestic scientists have also solved many questions on the provisions adaptation of the human capital famous theoretical concepts to national economy realities and needs, formulated sufficiently significant innovative solutions and recommendations for their use in the practice of enterprise management. This is evidenced by numerous publications addressing the problem issues of methods, models, techniques and technologies for managing enterprise human capital [1-2], measuring, analyzing and evaluating its value [3-8], accounting and controlling [9-10], investing in development [11-14], influence on motivation and the behavior of its carriers [15-16], and so on.

Differentiation of modern enterprise human resources on such features as human, intellectual, social, structural, consumer, emotional, competences, etc. capital is meaningful in the study of apparently specific properties of these components manifestations in the enterprise' capitalization of their activities results. However, more and more researchers come to the conclusion that it is the complex of all capital enterprise intangible components previously allocated by scientists become "the main form of its capitalization" [17] and "creations of value" [18], and "raising the level of human capital intellectualization" becomes an important task "leaders of all levels management" [19].

Thus O. A. Grishnova [17] analyzes the totality of human, intellectual and social capital, the common features of which are such economic characteristics as "resourcefulness, profitability and convertibility", O. M. Sobko [18] quite rightly calls "individual", "collective" and "social" intellectual capital (which is an integral part of the HC) are nothing more than "intellectual generators of the value of the enterprise", and O. Yu. Amosov and N. L. Gavkalo assert that "Human 
capital formation and accumulation is possible only with the provision of intellectualization process ...", which is understood as “... the process of human capital intellectual level gradual improvement on the basis of information, knowledge, skills and abilities synthesis of an individual, ..." [19].

On this basis we note that most of the common characteristics of the above-mentioned enterprise capital intangible components are derived from human intelligence and the generated results wich are concluded by him, that are called intellectual products. That is certain features commonality of all kinds of intangible capital, and primarily LC, is determined by the source of their formation - a person a "separate individual", an elementary carrier and a user with inherented individual intelligence (II).

So, following the logic of prof. O. A. Grishnova [17], it should be recognized that the basis of what "we know, know and can" (HC) is availability stipulation of intelligence presence in any individual, that "intellectual capital is a cognitive component of the $\mathrm{HC}$ plus a personal intellectual property" (IC), that is - intellectual production of own intelligence use by the same individual, and social capital (SC), being "a kind of complement, a catalyst for other forms of capital", which "facilitates the individual $\langle\ldots .$.$\rangle access to new$ knowledge and skills" is also a characteristic of individual intelligence ability to the "convertation HC, IC and SC".

At the same time, although prof. O. A. Grishnova states that "social capital" is an attribute of purely interpersonal relations [17], we stress the well-known fact that the individual's intelligence orientates his behavior towards personal goals (egoism or $\mathrm{I}+\mathrm{I}$ ), or towards society interests (altruism or I+THEY). Thus, the SC also acts as a product and a characteristic of elementary carrier individual intelligence.

\section{ILLUMINATION OF THE PREVIOUSLY UNSOLVED PART OF THE GENERAL PROBLEM}

However, the scientific views evolution on the processes and objects of such an economic category as enterprise HC study, interpreting the latter as " $\ldots$ formed and developed as a result of investment and accumulated by a person a certain stock of health, knowledge, skills, abilities, motivations that are purposefully used in one or another field of economic activity, contributes to the growth of labor productivity and, as a result, affects the growth of its owner income, the enterprise profit and national income" [16], has not yet given scientifical and theoretical fundamental model substantiation of formation, preservation, multiplication and company $\mathrm{HC}$ effective use, which is based on its elementary carrier - the person and his/her intelligence.

Given the above, the main element of scientific novelty in the presented study should be considered the rationale for a new approach to human capital management processes implementation, based on the first proposed graphoanalytic model - the spatial matrix of personality intellectual characteristics.

\section{THE PURPOSE OF THE PAPER}

The purpose of this paper is to develop an intellectual characteristic model of elementary carrier for human capital as a tool for managing the processes of planning, formation, development and efficient use of economic entity human capital.

\section{DISCUSSION OF RESULTS}

The resut of domestic and foreign publications analysis allows us to assert that both LC, IR, and SC and all other possible components of intangible capital are, first of all, products of the individual intelligence use, that is, the results of human intellectual activity.

Therefore, in our opinion, the new possibilities for formation, development and proper use management of such intangible capital of the individual as the HC, the IC, the SC, etc. should be sought and expected in the study of the $\mathrm{HC}=\mathrm{F}(\mathrm{II}), \mathrm{IR}=\mathrm{F}(\mathrm{II})$ and $\mathrm{SC}=\mathrm{F}(\mathrm{II})$ functional dependencies, that is resulted in planned and implemented, necessary and appropriate changes first in the individual intellect of the person through the intellectualization of the latter one, as well as manifestations of the changes made to obtain the necessary changes in all other derivative characteristics and the results of its intellectual activity with the corresponding levels of HC, IR and SC achievement.

The answer to the task of finding new possibilities for managing changes in the formation, development and use of II, as the basis for the formation, development and use of HC, IC, SC of a separate individual, may subsequently be extrapolated to formulate appropriate recommendations for a certain set of similar characteristics elementary carriers of any community (groups, divisions, enterprises, etc.).

All this, however, requires searching or creating a model not only for the human intelligence phenomenon, but for creating the model of those II characteristics that are the most important for the effective performance of its carrier in a particular people community, and may be subject to necessary and meaningful changes under management influence.

For the enterprise II elementary carrier it is suggested to consider its creative ability, for the differentiation of wich can be used with the suggested criteria of the pyramid of human community intellectual stratification into ordinary, extraordinary and elite intelligence, where:

- Ordinary II (OI) is used by its carrier to solve problems and meet needs based on the acquired knowledge and experience that do not require intellectual effort to create new intelligent products.

- Extraordinary II (ExtrI) besides solving problems and satisfying the needs of the advanced level based on the acquired knowledge and experience, also solve problems and satisfy needs requiring special knowledge, new experience and intellectual effort to create new intelligent products.

- Elite II (EI), in addition to solving two previous levels problems and needs, focuses on identifying, formulating and solving problems that require significant specialist knowledge, experience, and intellectual efforts for their creative perfection and modification. 
As the next important characteristics of the II elementary carrier for the enterprise if is suggested the criterion of sociality of the latter, under which we will understand the formed upbringing, knowledge and experience, the propensity to behavioral manifestations identified by science as selfishness, selfish altruism or altruistic egoism (rationalism) and altruism, which on V. V. Bilotserkivtsi's rightful opinion “... still remains insufficiently open in economic science and requires additional research" $[20$, p. 10]. It can be argued that:

- Selfish II (SeI) uses the system of value orientations formed in its carrier, the main motive and evaluation criterion of which is own interests satisfaction priority.

- Rational II (RI) uses the system of value orientations formed in its carrier, which are manifested in acts of preferential choice of him balanced self-altruistic behavior with respect to the surrounding people.

- Altruistic intelligence (AlI) uses the system of value orientations formed in its carrier, the main motive and criterion of moral evaluation of which is the satisfaction of another person or people interests.

Another undeniably important characteristic of the II elementary carrier within any enterprise is, in our opinion, generated by its intelligence the desire to obtain a certain status in the pyramid of personnel hierarchical stratification.

Note that the division of LC in various positions was proposed in [21, p. 191] on the criteria of "salary", "tuition costs" and "social insurance costs". However, reflecting the official expenses for the maintenance of elementary carrier in a certain position and arguing that "... the investment itself is a manifestation of human potential and human capital", the author ignored his intellectual ability to perform in this post an important function of the "intellectual generator of the value of the enterprise". In this regard, we propose to differentiate the status characteristics of the II elementary carriers for their ability to perform office functions at the following three levels:

- The executor II (ExI) consciously prefers to perform routine, stereotyped, standard activities, minimizing own responsibility for group results (for example, "X people" in D. McGregor motivation theory [22], "followers" in the "matrix of leadership" [23], "companions" in the coordinates of "individualismsynergism" [24]).

- The manager II (MI) consciously assumes responsibility for the joint activities of subordinates group in results reaching process planned by group's leadership (for example, "people Y" in D. McGregor motivation theory [22], "co-workers" in the "matrix of leadership" [23], "professionals" and "like-minded people" in coordinates "individualism-synergism" [24]).

- $\quad$ The leader II (LI) consciously wants to take the leading position in the group and possesses all the qualifications and competences necessary for it (for example, "leaders" in the "leadership matrix" [23] and "leaders" in [24]).

Using the above interpreted characteristics of II elementary media creative ability, social orientation and status, interpreted in the form of options continuum in increasing their value for "enterprise value generating", you can create three basic two-dimensional matrices of intellectual characteristics in coordinates "creative ability - social ability" , "creative ability - status ability" and "social ability - status ability" (Fig. 1).

Proceeding from the fact that the "matrix" concept allows us to interpret the data on the set of any characteristic elements or features of the object of research, evaluation, diagnosis, planning, etc. (in this case, the "intelligence of the individual") new variants of their sharing, interaction and new effects from it, matrices can become the information source and the tool for research, evaluation, diagnosis and planning of element necessary transformations with desired effects [25].

Thus, analyzing, for example, the matrix "creative ability - social ability", it can be seen that for group (enterprise) interests it will be more useful and important combinations of such intellectual characteristics of a person as "elite intelligence - altruistic intelligence" (sub-plane at characteristic intersection EI-AlI, Fig. 1a), "elite intelligence - leader's intelligence" (EI-IL, Fig.1b) and "altruistic intelligence - leader's intelligence" (AlI-IL, Fig. 1).

In this case, the intellectual characteristics of all other possible combinations will be worse in terms of group interests. However, the number of acceptable combinations should include all sub-planes, where the characteristics of individuals with elite and extraordinary, altruistic and rational, leadership and managerial intelligence are crossed.

The combination of "ordinary intelligence - selfish intelligence" (OI-SeI), "ordinary intelligence - executor intelligence" (OI-ExI) and "selfish intelligence - executor intelligence" (SeI-ExI) will characterize a person with a minimal group (enterprise) oriented interest intellectual characteristics. Unacceptable variants should also include sub-planes, which include the ordinary, selfish intelligence of a simple performer.

By combining three two-dimensional matrices according to the person's intelligence corresponding characteristics, we obtain the spatial (three-dimensional) matrix of person intellectual characteristics presented in Fig. 2.

It is obvious that in this spatial matrix, the intellectual characteristics of a person with a maximum (MAX) utility potential in securing group (enterprise) interests through the "generation of enterprise value" are described by the triad of coordinates "elite intelligence - altruistic intelligence - leader intelligence " (EI-AlI-LI, Fig. 2), and to the number of acceptable combinations in the spatial matrix should include sub-spaces where the characteristics of individuals with elite and extraordinary, altruistic and rational, leadership and managerial intellect are crossed.

In this case, any of the 25 other spatial matrix subspaces will correspond to person intellectual characteristics with a lower potential of group (enterprise) "cost generation" ability. However acceptable, again, should be considered sub-spaces with characteristics of elite and extraordinary, altruistic and rational, leadership and managerial intelligence. 


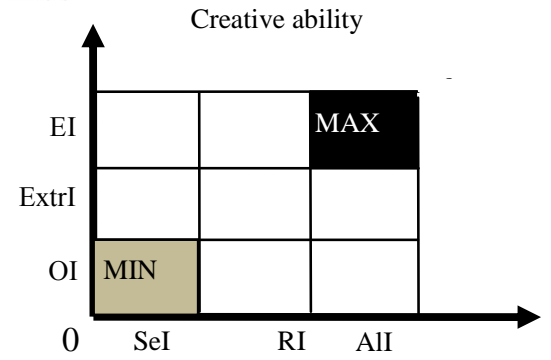

Social ability

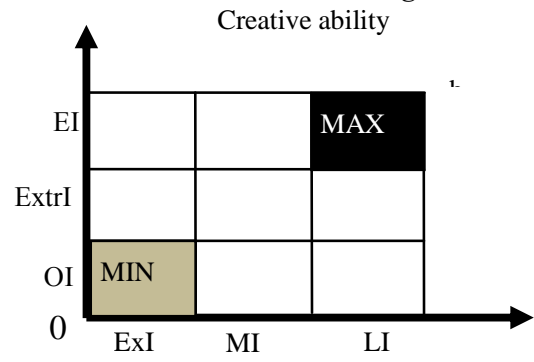

Status ability

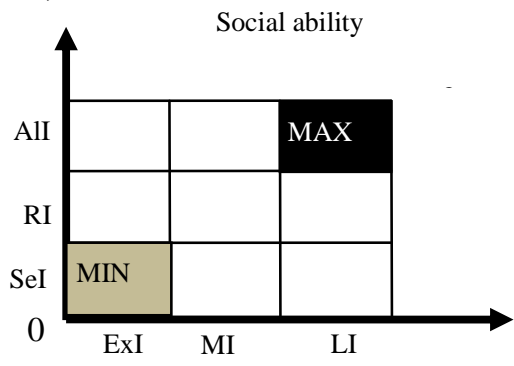

Status ability

Fig. 1 Two-dimensional matrix of characteristics of intelligence of the person in coordinates: "creative ability - social ability", b) "creativity ability - status ability", c) "social ability - status ability"

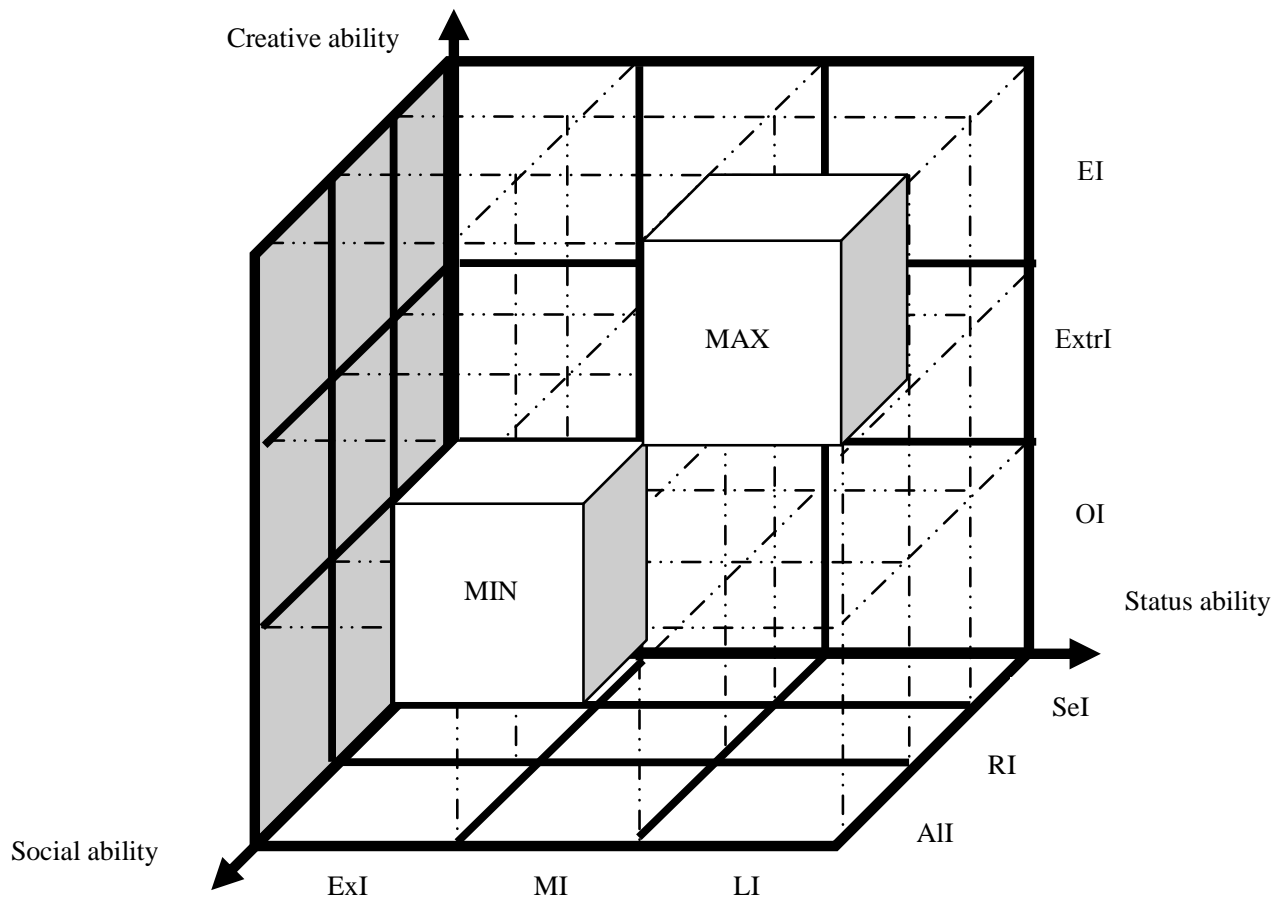

Fig. 2. The spatial matrix of the intellectual characteristics of the individual in the coordinates of "creative ability - social ability - status ability" and positioning in it the characteristics of persons with a minimum (min) and maximum (max) "ability to generate the enterprise cost"

Characteristics of persons with a minimum (MIN) potential of group (enterprise) utility are described by the triad "ordinary intelligence - selfish intelligence - executor intelligence" (OI-SeI-ExI, Fig. 2), as well as all sub-spaces in which there are components of ordinary, selfish, and purely executive intelligence.

Given the selection and use of appropriate test tools for testing and evaluation of team (enterprise) staff on the ability of each group member to creativity, sociality and status based on the proposed matrix interpretations of individual intellectual characteristics criteria, the information obtained will enable the positioning of any group (enterprise employee) member in 9 sub-planes of each two-dimensional matrix (Fig. 1), or in 27 sub-spaces of three-dimensional matrix (Fig. 2).

The organization and testing of all $\mathrm{N}$ group (enterprise) staff members and the differentiation of the latter by creative, social and status intellectual characteristics in proposed matrix space can and should be the source of management information for the evaluation, analysis, planning and implementation of needs for the development of individuals intellectual characteristics and their collectives, that is, contribute to implementation and proper use of all development management functions.

\section{CONCLUSION}

The practical value of the proposed approach is that the above-mentioned planar or spatial matrices can become a useful tool for processes managing of creating, developing and using any components of enterprises intangible capital (HC, IC, SC, etc.), which determine improving these characteristics possibilities due to managerial functions traditional complex implementation aimed at achieving by the person or their group (enterprise) education, qualifications, knowledge, experience necessary level and hence the ability of their carriers to productive, efficient and high quality work.

The use of the spatial matrix by economic entities management regardless of their activity will create the following opportunities for state and prospects improvement of their human capital development:

- through tests and surveys to research, analyze, evaluate and account the intelligence state of individual, their groups or the whole team; 
- to plan the incremental changes in the intelligence of any person (training plans);

- implement incremental displacement through education, experience and career management (implementation management: social filters and elevators);

- to motivate;

- to control.

Possibilities of practical testing of the model - the spatial matrix will become more accessible, provided the selection of existing and authoring tools for assessing the intellectual characteristics of the individual, which will be the subject of authors further scientific research.

At the same time, by means of a matrix, enterprise (group) staff differentiation by intellectual characteristics which are necessary in one or another position (so called "competence files") will allow as a result of comparison with the estimates received by employees and detected deviations, obtain the valuable management information for making decisions on:

- correspondence/inconsistency of a particular employee with the position necessary intellectual characteristics;

- needs, possibilities and expediency of development of enterprise personnel intellectual characteristics;

- preparation of training programs on incremental increase of each employee and the entire enterprise staff intellectual characteristics;

- planning and implementation of incremental displacement (career management) of workers using social elevators and filters;

- $\quad$ workers motivation program development for their acquisition of IC and $\mathrm{HC}$.

Since the enterprise changes necessary for all components of its intangible assets (HC, IC, SC, etc.) can be purposefully changed only through changes in its carriers intelligence (because the absence of the latter eliminates all other derivatives of intangible assets structural components), this intellectual characteristic system will be determined by the ability of any enterprise employee to creative work with added value or, in other words, the quality of an individual and aggregate employee of the enterprise, company, corporation, state.

\section{REFERENCES}

[1] V. M. Lich, The human capital of Ukraine: the state, problems, prospects of reproduction. Kyiv, Ukraine: KNUBA, 2009. [in Ukrainian].

[2] N. V. Zaitseva, "Concept of Modeling of Human Capital Management of an Enterprise", Scientific Papers of Poltava State Agrarian Academy. Economic Sciences, no. 2 (5), pp. 115-120, 2012. [in Ukrainian].

[3] T. V. Davydyuk, "Human Capital as an Object of Valuable Measurement in Accounting", Problems of the Ttheory and methodology of accounting, control and analysis, no. 2 (23), pp. 73 80, 2012. [in Ukrainian].
[4] L. V. Kovalenko, and A. P. Dolzhikova, "Analysis of the human capital of the enterprise as a key competence", Economic Space, no. 75, pp. 191-199, 2013. [in Ukrainian].

[5] K. V. Tymoshenko, "Analysis of Methods for Assessing Human Capital in the Enterprise", Bulletin of the Economy of Transport and Industry, no. 44, pp. 192-197, 2013. [in Ukrainian]

[6] O. I. Sakhnenko "Methods of Estimation of Human Capital", Economics and Society, no. 10, pp. 24-27, 2013. [in Ukrainian]

[7] A. M. Turilo, and R.V. Korolenko, "The System of Estimation of Human Capital of an Employee of an Enterprise", Agrosvit, no. 9, pp. 31-36, 2011. [in Ukrainian].

[8] G. Syrotyuk, and L. Petryshyn, "Essence and Methods of Human Capital Assessment", Agrarian Economics, vol. 8, no. 3-4, pp. 9-17, 2015. [in Ukrainian].

[9] M. V. Resler "Human Capital as an Object of Accounting", Scientific Bulletin of the IHU, vol. 12, pp. 234-240, 2015.

[10] N. M. Korolyuk, "Human Capital Controlling System", Scientific Bulletin of the Chernivtsi Trade and Economic Institute of KNTEU. Economic Sciences, vol. 1 (37), pp. 163-173, 2010. [in Ukrainian].

[11] O. V. Zakharova, Management of Investment in Human Capital: Methodology, Assessment, Planning. DVNZ DonNTU, Donetsk, Ukraine: DonNTU, 2010. [in Ukrainian].

[12] V. F. Goryachuk, "Investments into human capital and returns from them", Economy: Realities of Time, no. 1 (2), pp. 34-39, 2012. [in Ukrainian].

[13] O. M. Chechel, "Investing in human development as a priority direction in the formation of human capital", Economy and the State, no. 3, pp. 86-88, 2010. [in Ukrainian].

[14] L. A. Kvyatkovskaya, "Modern Investment Trends in Human Capital", Economy and management of enterprises, industries, and national economy, Bulletin of KrNU named by M. Ostrogradsky, vol. 1 (78), pp. 138-142, 2013. [in Ukrainian].

[15] L. K. Semen, "Motivational aspects of human capital development in the evaluation of the representatives of the intellectual elite", Sustainable development of the economy, vol. 1, pp. 3-9, 2010. [in Ukrainian].

[16] O. B. Yurchenko, "Motivation as a significant factor in the formation of human capital", Scientific Bulletin of NLTU of Ukraine, vol. 20 (4), pp. 156-159, 2010. [in Ukrainian].

[17] O. A. Grishnova, "Accumulation of the human, intellectual and social capital of the enterprise as the main form of its capitalization", Bulletin of the Donetsk University of Economics and Law, vol. 1, pp. 10-13, 2011. [in Ukrainian].

[18] O. M. Sobko, "Novelization of the vectors of constructing the mechanism of creation of the value of the enterprise", Bulletin of the ONU named by I. I. Mechnikov, vol. 2/2, no. 20, pp. 81-85, 2015. [in Ukrainian].

[19] O. Yu. Amosov, and N. L. Gavkala, "Features of the formation of human capital by means of its intellectualization", Eastern Europe: Economics, Business and Management, vol. 3 (03), pp. 271-273, 2016. [in Ukrainian].

[20] V. V. Bilotserkivets, "Dilemma of economic development: between altruism and selfishness", Economic Nobel Bulletin, vol. 1 (8), pp. 1016, 2015. [in Ukrainian].

[21] R. V. Korolenko, "Theoretical Approaches to the Definition of the "Human Capital", All-Ukrainian Scientific and Production Magazine “Innovative Economics”, vol. 2, pp. 189-192, 2013. [in Ukrainian].

[22] D. Gannon, and A. Boguszak, "Douglas McGregor's Theory X and Theory Y", CRIS - Bulletin of the Centre for Research and Interdisciplinary Study, vol. 2013 (2), pp. 85-93, 2013.

[23] O. Lyuty, R. Panasyuk and V. Petrenko, "Differentiation of human resources of socio-economic systems according to the matrix of leadership", in Ukraine-EU. Innovations in Education, Technology, Business and Law: a collection of international scientific papers, Chernihiv, Ukraine: CNUT, 2018, pp. 241-243. [in Ukrainian].

[24] Yu. Navruzov, "Command Roles: Introducing Changes: Original Art", Kyiv-Mohyla Business Studio, vol. 2, pp. 20-25, 2002. [in Ukrainian].

[25] M. I. Ivanova, and N. V. Yashkina, "Using the complex of matrix methods of strategic analysis of activity of production enterprises", Economy and the State, vol. 6, pp. 86-90, 2014. [in Ukrainian]. 